\title{
PENGARUH KESEIMBANGAN KEHIDUPAN KERJA (WORK LIFE BALANCE) DAN KEPUASAN KERJA TERHADAP LOYALITAS GURU SMK SWASTA DI KECAMATAN CAKUNG JAKARTA TIMUR
}

\begin{abstract}
ANISA RAHMAWATI*
Abstract: The objective of this research is to know the effect of work life balance and job sastisfaction toward teacher's loyalty of the private vocational high school at cakung district east Jakarta.The research was conducted using survey method with quantitative approach and path analysis technique. The population of this research is 772 teachers. Research samples selected as much as 263 teachers using simple random sampling technique. The data obtained through questionnaires and analyzed using path analysis techniques. Based on the results of data analysis in this research it is concluded: (1) the work life balance have positive direct effect to loyalty; (2) job sastisfaction have positive direct effect to loyalty; (3) the work life balance have positive direct effect to job sastisfaction. The loyalty can be improved through improvement of work life balance and job sastisfaction.
\end{abstract}

Keywords: loyalty, work life balance, and job sastisfaction.

\section{PENDAHULUAN}

Sebagai tenaga profesional yang berdiri di garis depan dalam dunia pendidikan, guru harus handal dan benar-benar tampil profesional sehingga mampu melahirkan generasi masa depan yang cerdas dan berkarakter. Mereka harus selalu memiliki kesempatan untuk meng-upgrade kemampuan diri sehingga sanggup menjadi guru inspiratif, bukan sekadar guru kurikulum yang tugas kesehariannya hanya dibatasi tembok ruang kelas.

Lebih lanjut, pendidik juga harus memiliki capability dan loyality, yakni pendidik itu harus memiliki kemampuan dalam bidang ilmu yang diajarkannya, memiliki kemampuan teoritis tentang mengajar yang baik, dari mulai perencanaan, implementasi sampai evaluasi, dan memiliki loyalitas keguruan, yakni loyal terhadap tugas-tugas keguruan yang tidak semata di dalam kelas, tetapi sebelum dan sesudah kelas.

Sekolah dalam mencapai tujuan seringkali dihadapkan pada hambatan-hambatan berupa rendahnya mutu dan kesejahteraan guru, terlebih pada guru hononer dan non PNS, yang dapat mengganggu loyalitas. Seperti kejujuran dan loyalitas guru juga diuji dalam pelaksanaan Ujian Nasional (UN). Kecurangan pelaksanaan ujian nasional tidak jarang melibatkan guru. Guru yang seharusnya menjadi contoh bagi siswanya namun karena loyalitasnya rendah malah ikut curang dalam pelaksanaannya.

Rendahnya loyalitas salah satunya disebabkan oleh keseimbangan kehidupan kerja yang kurang. Seperti yang dikatakan Hye Kyoung Kim (2014:40) bahwa, "the experience of work-life balance generates feelings of loyalty to the organization and increases affective commitment. Affective commitment is an emotional attachment to the organizations or the employers which can cause employees to want to remain with the organizations"

Selain keseimbangan kehidupan kerja, rendahnya loyalitas juga dipengaruhi oleh kepuasan kerja. Seperti yang dikatakan Mai Ngok Huem (2011:93) bahwa, "all the objectives of this study has been succesfully obtained, firtstly to explained the relationship between

* Ketua Yayasan TK Anak Bangsa Wisma DPR RI Kalibata 
job satisfaction and employee loyalty, the fourthly.. to identify wich are factors (including job satisfaction) that have the most effect and how do those factors directly and indirectly affect to employee loyalty."

Pengaruh keseimbangan kehidupan kerja dan kepuasan kerja untuk meningkatkan loyalitas dapat dilihat dari pernyataan Ion Lazaar (2000:208) yang menyatakan bahwa, "the benefit of work life balance: increased job satisfaction, greater sence of job security, enhanched control over work life environment, reduce job stress levels, better phisycal and mental health." Maka dari itu peneliti ingin mengkaji secara ilmiah apakah keseimbangan kehidupan kerja dan kepuasan kerja berpengaruh terhadap loyalitas guru.

\section{Loyalitas}

Secara teknis, Loyalitas berasal dari kata loyal yang berarti setia seperti dijelaskan oleh Niehoff (2001:4) yang berpendapat bahwa, "loyalty was defined in terms of active behaviors that demonstrate pride in and support for the organization. Defending the organization against criticism, emphasizing the positive aspects of the organization, and refraining from complaining about the organization would be examples of such behaviors." Loyalitas didefinisikan dalam hal perilaku aktif yang menunjukkan kebanggaan dan dukungan bagi organisasi. Membela organisasi terhadap kritik, menekankan aspek positif dari organisasi, dan menahan diri dari mengeluh tentang organization menjadi contoh perilaku tersebut.

Sejalan dengan pernyataan Robbins dan Judge (2011:119) yang mengatakan bahwa, "loyalty is dissatisfaction expressed by passively waiting for condition to improve." Loyalitas merupakan perasaan tidak puas yang dinyatakan dengan menunggu secara pasif sampai keadaan membaik sehingga orang lain yang melihat berpikir bahwa karyawan tersebut loyal.

Selanjutnya Stephen Griffin (2002:2) yang menjelaskan bahwa, "loyalty is defined as nonrandom purchase expressed over time by some decision making unit." loyalitas ditunjukkan pada suatu perilaku pembelian rutin yang didasarkan pada unit pengambilan keputusan. Maksudnya orang yang memiliki loyalitas tinggi adalah seseorang yang melakukan sesuatu secara berulang didasakan keputusannya karena adanya kepuasan dalam dirinya.

Penjelasan lain tentang loyalitas dijelaskan oleh Koetler (2003:97) yang mendefinisikan bahwa, "loyalty is an old-fashioned word describing being deeply commited to one's country, family or friends." Loyalitas adalah sebuah bentuk lama yang menggambarkan kepercayaan mendalam terhadap suatu negara, keluarga atau teman.

Selanjutnya Colquitt et al (2011:79) yang menjelasksan bahwa, "loyalty defined as a passive, contructive response that maintains public support for the situation while the individual privately hopes for improvement." Tanggapan membangun dengan pasif adalah membangun dukungan dari khalayak terhadap situasi yang sedang terjadi, sementara dari diri berharap adanya perbaikan. Membangun dukungan dapat dilakukan dengan berbagai cara seperti mengajak, menghimbau, memotivasi serta mengingatkan bahwa misi organisasi harus tercapai.

Penjelasan lain tentang loyalitas dijelaskan oleh Sistare (2009:171) yang menjelaskan bahwa, "loyalty is commitment for the long term." Loyalitas juga dapat diartikan sebagai komitmen karyawan dalam jangka panjang. Karyawan yang berkerja dalam waktu lama merasa puas dengan pencapaian yang diperoleh, dengan begitu karyawan tersebut bertahan dan berkomitmen di perusahan tersebut. 
Selanjutnya Mowday, Porter, dan Steers (1982:185) menyatakan bahwa, "defined is the relative stregth on an individual's identification with and involement in a particular organization." Definisi tersebut menunjukan bahwa loyalitas memiliki arti yang lebih dari sekedar loyalitas pasif, namun melibatkan hubungan aktif dan keinginan karyawan memberikan kontribusi yang berarti pada organisasinya.

Berdasarkan konsep di atas, maka dapat disintesiskan bahwa loyalitas adalah kepatuhan dan kesetiaan seseorang pada organisasi yang tercermin pada sikap dan perilaku, dengan indikator: dukungan terhadap organisasi, partisipasi aktif, disiplin, tanggung jawab dan sikap kerja yang positif.

\section{Keseimbangan Kehidupan Kerja}

Menurut Guest, Greenhaus, Collins dan Shaw (2003:527), "an examination, of the boarder of work life balance would require assessment of time, involvement, and community membership. It would be useful to study the balancece between work and the aggregate of other life roles as wel as the balance between pairs of specific roles." Pemeriksaan, dari perbatasan keseimbangan kehidupan kerja akan memerlukan penilaian waktu, keterlibatan, dan keanggotaan masyarakat. Ini akan berguna untuk mempelajari keseimbangan antara pekerjaan dan agregat peran kehidupan lainnya sebagai wel sebagai keseimbangan antara pasangan peran khusus.

Penjelasan lain tentang menurut Lockwood (2003:4), "work life balance as a State equilibrium in wich the demands of both a pearsons job and personal life are equal. Work/life balance from the employee viewpoint: the dilemma of managing work obligations and personal/family responsibilities. Work/life balance from the employer: the challenge of creating a supportive company culture where employees can focus on their jobs while at work." Diartikan sebagai suatu keadaan seimbang pada dua tuntutan dimana pekerjaan dan kehidupan seorang individu adalah sama. Dalam pandangan karyawan, work-life balance adalah pilihan mengelola kewajiban kerja dan pribadi atau tanggung jawab terhadap keluarga. Dalam pandangan perusahaan; tantangan untuk menciptakan budaya yang mendukung di perusahaan dimana karyawan dapat focus pada pekerjaan mereka.

Selanjutnya Schermerhorn (2012:314) mengatakan bahwa, "work life balance is a broad concept including proper prioritizing between "work" (career and ambitio) on the one hand and "life" (health, pleasure, leisure, family and spiritual development\} on the other." Keseimbangan kehidupan kerja adalah konsep yang luas, termasuk memprioritaskan dengan tepat antara "pekerjaan" (karir dan ambisi) di satu sisi, dan "kehidupan" di sisi lain, mencakup kesehatan, kesenangan/hobi, rekreasi, keluarga dan pengembangan spiritual seseorang.

Penjelasan lain tentang keseimbangan kehidupan kerja dijelaskan oleh State Services Commission (2005:46) mengatakan bahwa, "consider wich work-life balance issue seems to be most prevalent: a) work place issues: work life balance issues generated by aspects of the workplace (nature of work environment, types of workplaces, issues in the workplace), b) life issues; work life balance issues generated by differentlife needs (need for time for families and community, need for personal time like leisure/recreation, needs as a member of a specific group)." Dijelaskan bahwa hal-hal berikut di atas termasuk dalam cakupan kajian keseimbangan kehidupan kerja, yaitu: (a) Aspek pada tempat kerja, terdiri dari : jenis pekerjaan, tipe tempat kerja, dan masalah di tempat kerja misalnya beban kerja yang tidak masuk akal. (b) Kebutuhan hidup, terdiri dari : kebutuhan waktu untuk keluarga dan masyarakat misalnya perawatan anak, kebutuhan waktu untuk pribadi karyawan misalnya rekreasi, dan kebutuhan waktu sebagai anggota kelompok tertentu. 
Berdasarkan beberapa konsep dan pengertian di atas, work-life balance dapat disintesiskan sebagai proporsi yang seimbang antara waktu, emosi dan sikap pada tuntutan pekerjaan (organisasi) dan kehidupan seseorang diluar pekerjaan, seperti kehidupan keluarga, kehidupan sosial, kehidupan spiritual, hoby, kesehatan, rekreasi dan pengembangan diri, dengan indikator: keseimbangan dalam pengelolaan waktu, keseimbangan dalam pemenuhan harapan, keseimbangan keterlibatan, dan keseimbangan kepuasan.

\section{Kepuasan Kerja}

Robbins dan Judge (2011:114) mendefinisikan kepuasan kerja bahwa, "job satisfaction is a positive feeling about a job resulting from an evaluation of its characteristics." Kepuasan kerja adalah perasaan positif tentang pekerjaan yang dihasilkan dari evaluasi karakteristik.

Penjelasan lain tentang kepuasan kerja menurut George dan Jones (2003:71) mengatakan, "job satisfaction is the collection of feelings and beliefs that people have about their current jobs. People's levels or degrees of job satisfaction can range from extreme satisfaction to extreme dissatisfaction. Recall from the opening case how job satisfaction levels are very high at Nugget Markets. In addition to having attitudes about their jobs as a whole, people also can have attitudes about various aspects of their jobs such as the kind of work they do, their coworkers, supervisors, or subordinates, and their pay." Kepuasan kerja adalah kumpulan perasaan dan keyakinan bahwa orang miliki tentang pekerjaan mereka saat ini. Tingkat masyarakat atau derajat kepuasan kerja dapat berkisar dari kepuasan ekstrim ketidakpuasan yang ekstrim. Ingat dari kasus pembukaan bagaimana tingkat kepuasan kerja yang sangat tinggi di Nugget Markets. Selain memiliki sikap tentang pekerjaan mereka secara keseluruhan, orang juga dapat memiliki sikap tentang berbagai aspek pekerjaan mereka seperti jenis pekerjaan yang mereka lakukan, rekan kerja mereka, supervisor, atau bawahan, dan gaji mereka.

Selanjutnya Schermerhorn et.al (2012:72) mengatakan bahwa, "job satisfaction is the degree to which an individual feels positive or negative about a job." Kepuasan kerja adalah sejauh mana seorang individu merasa positif atau negatif tentang pekerjaan.

Sejalan dengan pernyataan Locke dalam Anderson et.al (2001:25) mengatakan bahwa, "job satisfaction is a pleasurable or positive emotional state resulting from the appraisal of one's job or job experiences." Kepuasan kerja adalah keadaan emosi yang menyenangkan atau positif yang dihasilkan dari penilaian pekerjaan atau job pengalaman seseorang.

Penjelasan lain tentang kepuasan kerja menurut Mullins (2012:700) mengatakan bahwa, "job satisfaction is a complex and multifaceted concept, wich can mean different things to different people. Job satisfaction is usually linked with motivation, but the nature of this relationship is not clear. Satisfaction is not the same as motivation. Job satisfactionis more of an attitude, an internal state. It could, for example, be associated with a personal feeling of achievement, either quantitaviveor qualitative." Kepuasan kerja adalah konsep yang kompleks dan beragam, yang dapat berarti hal yang berbeda untuk orang yang berbeda. Kepuasan kerja biasanya dikaitkan dengan motivasi, tetapi sifat hubungan ini tidak jelas. Kepuasan adalah tidak sama dengan motivasi. Kepuasan kerja lebih dari sikap, keadaan internal. Itu bisa, misalnya, dikaitkan dengan perasaan pribadi prestasi, baik kualitatif kuantitatif.

Berdasarkan konsep dan pengertian di atas, maka dapat disintesiskan kepuasan kerja adalah respon perasaan senang atau tidak senang atas pekerjaan berdasarkan harapan adanya imbalan yang diberikan oleh organisasi, dengan indikator: perasaan terhadap kondisi kerja yang mendukung, perasaan terhadap penghargaan, perasaan 
terhadap hubungan dengan atasan, terhadap hubungan dengan rekan kerja, perasaan terhadap pekerjaan itu sendiri, perasaan terhadap kesempatan berprestasi, dan perasaan terhadap penghargaan yang diterima.

\section{METODE PENELITIAN}

Penelitian ini dilaksanakan di SMK Swasta di Jakarta Timur dengan unit analisis para guru di wilayah Kecamatan Cakung. Adapun target waktu pelaksanaan penelitian ini direncanakan selama 3 (tiga) bulan. Metode yang digunakan dalam penelitian ini adalah metode survey dengan bentuk kausal. Populasi target yang telah ditetapkan dalam penelitian ini adalah guru SMK Swasta di Jakarta Timur. Populasi terjangkau penelitian ini adalah guru SMK Swasta Jakarta Timur yang berada di wilayah Kecamatan Cakung yang seluruhnya berjumlah 772 guru yang diambil berdasarkan teknik Simple Random Sampling. Data yang dikumpulkan dalam penelitian dijaring melalui kuesioner yang berupa skala penilaian (rating scale) dengan sebaran skor antara 1 sampai dengan 5 .

Setelah dilakukan analisis deskriptif dilanjutkan dengan uji persyaratan analisis berupa uji normalitas, uji linearitas data dan keberartian regresi, dilakukan uji hipotesis dengan menggunakan teknik analisis jalur (path analysis).

\section{HASIL DAN PEMBAHASAN}

\section{Pengaruh Keseimbangan Kehidupan Kerja terhadap Loyalitas}

Hasil penelitan ini menunjukkan bahwa keseimbangan kehidupan kerja memberikan pengaruh positif secara langsung terhadap loyalitas. Besarnya pengaruh tersebut ditunjukkan oleh koefisien korelasi 0,602 dan koefisien jalur 0,481. Hal ini menujukkan bahwa keseimbangan kehidupan kerja dapat meningkatkan loyalitas guru. Niehoff (2001:4) yang berpendapat bahwa, "loyalty was defined in terms of active behaviors that demonstrate pride in and support for the organization. Defending the organization against criticism, emphasizing the positive aspects of the organization, and refraining from complaining about the organization would be examples of such behaviors." Loyalitas didefinisikan dalam hal perilaku aktif yang menunjukkan kebanggaan dan dukungan bagi organisasi. Membela organisasi terhadap kritik, menekankan aspek positif dari organisasi, dan menahan diri dari mengeluh tentang organization menjadi contoh perilaku tersebut. Sejalan dengan pernyataan Robbins dan Judge (2011:119) yang mengatakan bahwa, "loyalty is dissatisfaction expressed by passively waiting for condition to improve." Loyalitas merupakan perasaan tidak puas yang dinyatakan dengan menunggu secara pasif sampai keadaan membaik sehingga orang lain yang melihat berpikir bahwa karyawan tersebut loyal.

Hasil penelitian ini sejalan dengan pendapat Hye Kyoung Kim (2014:40) yang menyatakan, "the experience of work-life balance generates feelings of loyalty to the organization and increases affective commitment. Affective commitment is an emotional attachment to the organizations or the employers which can cause employees to want to remain with the organizations." Dalam penelitiannya ditemukan bahwa pengalaman Keseimbangan kehidupan kerja menghasilkan perasaan loyalitas kepada sekolah dan meningkatkan komitmen afektif. Komitmen afektif adalah keterikatan emosional dengan sekolaha atau instansi yang dapat menyebabkan guru ingin tetap dengan sekolahnya.

Hasil penelitian ini sejalan dengan pendapat Scholarius dan Mark (2014:19), "employees' attitudes toward their organizations and life are affected by work-life balance. Worklife balance is especially important when organization has to manage highly technical professional because their high commitment and loyalty is needed for the success of the organization." Yaitu, 
bahwa sikap guru terhadap sekolah dan kehidupan mereka dipengaruhi oleh Keseimbangan kehidupan kerja. Keseimbangan kehidupan kerja sangat penting saat organisasi harus mengelola profesional sangat teknis karena komitmen yang tinggi dan loyalitas yang diperlukan untuk keberhasilan sekolah.

Hasil penelitian ini sejalan dengan pendapat Nathalie Skinner dan Janine Chapman (2014:2), "observe evidence for a positive effect of organisational work-life balance practices on recruitment, retention, attendance (including turnover intention), and productivity. One explanation is that employees reciprocate with increased loyalty, effort and productivity in exchange for the organisation's practical assistance with managing work-life demands, and in appreciation for the organisation's indication of care and concern as demonstrated by work-life policies and practices." Terdapat efek positif praktek Keseimbangan kehidupan kerja bagi sekolah, terlihat pada perekrutan, retensi, kehadiran dan produktivitas. Salah satu penjelasan adalah bahwa guru membalasnya dengan peningkatan loyalitas, usaha dan produktivitas, sebagai bentuk apresiasi guru terhadap upaya sekolah untuk mengelola dan mempraktekkan prinsip Keseimbangan kehidupan kerja di lingkungannya. Dengan memperhatikan unsur-unsur kepedulian dan perhatian sekolah terhadap Keseimbangan kehidupan kerja gurunya, sebagaimana yang ditunjukkan selama ini dalam praktek dan kebijakan kehidupan kerja.

Merujuk dari teori tersebut dengan demikian terdapat pengaruh langsung positif keseimbangan kehidupan kerja terhadap loyalitas guru. Dengan kata lain semakin tinggi keseimbangan kehidupan kerja maka semakin meningkat loyalitas guru.

\section{Pengaruh Kepuasan Kerja terhadap Loyalitas}

Hasil penelitan ini menunjukkan bahwa kepuasan kerja memberikan pengaruh positif secara langsung terhadap loyalitas. Besarnya pengaruh tersebut ditunjukkan oleh koefisien korelasi 0,535 dan koefisien jalur 0,382. Hal ini menujukkan bahwa kepuasan kerja dapat meningkatkan loyalitas guru. Schermerhorn et.al (2012:72) mengatakan bahwa, "job satisfaction is the degree to which an individual feels positive or negative about a job." Kepuasan kerja adalah sejauh mana seorang individu merasa positif atau negatif tentang pekerjaan. Locke dalam Anderson et.al (2001:25) mengatakan bahwa, "job satisfaction is a pleasurable or positive emotional state resulting from the appraisal of one's job or job experiences." Kepuasan kerja adalah keadaan emosi yang menyenangkan atau positif yang dihasilkan dari penilaian pekerjaan atau job pengalaman seseorang. Sedangkan menurut Mullins (2012:700) mengatakan bahwa, "job satisfaction is a complex and multifaceted concept, wich can mean different things to different people. Job satisfaction is usually linked with motivation, but the nature of this relationship is not clear. Satisfaction is not the same as motivation. Job satisfactionis more of an attitude, an internal state. It could, for example, be associated with a personal feeling of achievement, either quantitaviveor qualitative." Kepuasan kerja adalah konsep yang kompleks dan beragam, yang dapat berarti hal yang berbeda untuk orang yang berbeda. Kepuasan kerja biasanya dikaitkan dengan motivasi, tetapi sifat hubungan ini tidak jelas. Kepuasan adalah tidak sama dengan motivasi. Kepuasan kerja lebih dari sikap, keadaan internal. Itu bisa, misalnya, dikaitkan dengan perasaan pribadi prestasi, baik kualitatif kuantitatif.

Hasil penelitian ini sejalan dengan pendapat Pandey dan Khare (2014:2), “...the findings of the research conclude that there is a significant impact of job satisfaction and organizational commitment on employee loyalty." Temuan penelitian menyimpulkan bahwa ada dampak yang signifikan dari pekerjaan kepuasan dan komitmen sekolah terhadap loyalitas kerja guru di sekolah tempat kerjanya. 
Hasil penelitian ini sejalan dengan pendapat Mai Ngok Huem (2014:93), "all the objectives of this study has been succesfully obtained, firtstly to explained the relationship between job satisfaction and employee loyalty, the fourthly to identify wich are factors (including job satisfaction) that have the most effect and how do those factors directly and indirectly affect to employee loyalty." Semua tujuan penelitian ini telah berhasil diperoleh, pertama untuk menjelaskan hubungan antara kepuasan kerja dan loyalitas guru, yang keempat, untuk mengidentifikasi yang mana adalah faktor (termasuk kepuasan kerja) yang memiliki efek yang paling dan bagaimana faktor-faktor langsung dan tidak langsung mempengaruhi loyalitas guru. Hasil penelitian ini juga sejalan dengan pendapat Luthans (2011:146), "whereas satisfaction is mainly concerned with the employee,s attitude toward the job and commitment is at the level of the organizational, a strong relationship between job satisfaction and organizationa; commitment has been found over the year." Sedangkan kepuasan terutama berkaitan dengan guru, sikap terhadap pekerjaan dan komitmen di tingkat sekolah, hubungan yang kuat antara kepuasan kerja dan organisasi ke komitmen telah ditemukan sepanjang tahun.

Merujuk dari teori tersebut dengan demikian terdapat pengaruh langsung positif kepuasan akerja terhadap loyalitas guru. Dengan kata lain semakin tinggi kepuasan kerja maka semakin meningkat loyalitas guru.

\section{Pengaruh Keseimbangan Kehidupan Kerja terhadap Kepuasan Kerja}

Hasil penelitan ini menunjukkan bahwa keseimbangan kehidupan kerja memberikan pengaruh positif secara langsung terhadap kepuasan kerja. Besarnya pengaruh tersebut ditunjukkan oleh koefisien korelasi 0,318 dan koefisien jalur 0,318. Hal ini menujukkan bahwa keseimbangan kehidupan kerja dapat meningkatkan kepuasan kerja guru. Lockwood (2003:4) menjelaskan, "work life balance as a State equilibrium in wich the demands of both a pearsons job and personal life are equal. Work/life balance from the employee viewpoint: the dilemma of managing work obligations and personal/family responsibilities. Work/life balance from the employer: the challenge of creating a supportive company culture where employees can focus on their jobs while at work." Work-life balance merupakan suatu keadaan seimbang pada dua tuntutan di mana pekerjaan dan kehidupan seorang individu adalah sama. Dalam pandangan karyawan, work-life balance adalah pilihan mengelola kewajiban kerja dan pribadi atau tanggung jawab terhadap keluarga. Dalam pandangan perusahaan; tantangan untuk menciptakan budaya yang mendukung di perusahaan dimana karyawan dapat focus pada pekerjaan mereka. Selanjutnya Schermerhorn (2012:314) mengatakan bahwa, "work life balance is a broad concept including proper prioritizing between "work" (career and ambitio) on the one hand and "life" (health, pleasure, leisure, family and spiritual development\} on the other." Keseimbangan kehidupan kerja adalah konsep yang luas, termasuk memprioritaskan dengan tepat antara "pekerjaan" (karir dan ambisi) di satu sisi, dan "kehidupan" di sisi lain, mencakup kesehatan, kesenangan/hobi, rekreasi, keluarga dan pengembangan spiritual seseorang.

Hasil penelitian ini sejalan dengan pendapat Lazaar (2000:208), "the benefit of work life balance: increased job satisfaction, greater sence of job security, enhanched control over work life environment, reduce job stress levels, better phisycal and mental health." Manfaat keseimbangan kehidupan kerja pada guru, yaitu meningkatnya kepuasan kerja, semakin tingginya keamanan kerja (job security), meningkatkan kontrol terhadap worklife environment, berkurangnya tingkat stres kerja, dan semakin meningkatnya kesehatan fisik dan mental. 
Menurut pendapat Susi dan Jawaharrani (2001:478), "over the last decade the evidence for business benefits of work life balance policies has been growing in volume and strength. The study show strong link between work-life balance policies and reduceed absenteeism, increased productivity and job satisfaction." Selama dekade terakhir bukti untuk keuntungan bisnis dari kebijakan keseimbangan kehidupan kerja telah berkembang dalam volume dan kekuatan. Penelitian menunjukkan hubungan yang kuat antara kebijakan kehidupan kerja keseimbangan dan mengurangi absensi, meningkatkan produktivitas dan kepuasan kerja.

Hasil penelitian Bashra Arif and Yassir Aftab (2014:28), "the objectives of studywas to find out the impact of work life balance on job satisfaction and organizational commitment among teaching employees of Univercity of Gujarat. At the end of aour discussion, it is concluded from the research that the employees work and life balance affects employees satisfaction and their commitment with the organization." Tujuan dari penelitian ini adalah untuk mengetahui dampak dari keseimbangan kehidupan kerja terhadap kepuasan kerja dan komitmen sekolah antara mengajar guru Univercity of Gujarat. Pada akhir diskusi, dapat disimpulkan dari penelitian bahwa guru bekerja dan keseimbangan hidup mempengaruhi kepuasan guru dan komitmen mereka dengan sekolah.

Merujuk dari teori tersebut dengan demikian terdapat pengaruh langsung positif keseimbangan kehidupan kerja terhadap kepuasan kerja guru. Dengan kata lain semakin tinggi keseimbangan kehidupan kerja maka semakin meningkat tingkat kepuasan kerja guru.

\section{PENUTUP}

Kesimpulan: Berdasarkan hasil perhitungan data penelitian dan hasil analisis data yang telah diuraikan, maka dapat di peroleh beberapa kesimpulan sebagai berikut: (1) keseimbangan kehidupan kerja berpengaruh langsung positif terhadap loyalitas guru. Artinya peningkatan keseimbangan kehidupan kerja mengakibatkan peningkatan loyalitas guru SMK Swasta di Kecamatan Cakung; (2) kepuasan kerja berpengaruh langsung positif terhadap loyalitas. Artinya peningkatan kepuasan kerja mengakibatkan peningkatan loyalitas guru SMK Swasta di Kecamatan Cakung; (3) keseimbangan kehidupan kerja berpengaruh langsung positif terhadap kepuasan kerja. Artinya peningkatan keseimbangan kehidupan kerja mengakibatkan peningkatan kepuasan kerja guru SMK Swasta di Kecamatan Cakung.

Saran: Untuk guru terkait dengan keseimbangan kehidupan kerja agar meningkatkan loyalitas dengan cara-cara sebagai berikut: (1) guru dapat melakukan keseimbangan dalam pengelolaan waktu datang, (2) bekerja dan pulang, (3) guru dapat melakukan keseimbangan dalam pemenuhan harapan yang di berikan sekolah, (4) guru dapat menempatkan diri dalam kegiataan di dalam sekolah maupun di luar sekolah, dan (5) guru dapat berinteraksi antara siswa dan rekan kerja. Kedua, saran untuk guru terkait dengan kepuasan kerja agar dapat meningkatkan loyalitas. Guru hendaknya (1) nyaman dengan lingkungan kerjanya, (2) perasaan puas terhadap penghargaan yang di berikan kepada guru, (3) perasaan terhadap hubungan dengan atasan, rekan kerja, (4) perasaan terhadap hubungan dengan rekan kerja, (5) guru menikmati pekerjaan yang diembankan kepadanya, dan (6) perasaan puas dengan promosi jabatan.

\section{DAFTAR RUJUKAN}

Brian P. Niehoff, Robert H. Moorman dan Gerald Blakely Jack Fuller, "The Influence of Empowerment and job Enrichment on Employee Loyalty in a Downsizing 
Environment," Group \& Organization Management, Vol. 26 No. 1, March 200193 113 (C) 2001 Sage Publications, Inc.

Chetna Pandey dan Rajni Khare, Impact of Job Satisfaction and Organizational Commitment on Employee Loyalti, International Journal vol.1 http:// www.Indianresearchjournals.com (diakses 2 Agustus 2014)

Clarke, M. Koch, The Work Family Interface; Differentiating balance and fit, Family and Concumer Sciences Research, Journal 33 (2004).

Colquitt, Jason A., Jeffry A. Lepine and Michael J. Wesson. Organizational Behavior: Improving Performance and Commitment in The Workplace. New York: McGraw-Hill Irwin, 2009.

Fred Luthans, Organizational Behavior (New York: McGraw-Hill, 2011).

Gibson, James L, et al. Organization: Behavior, Structure, Process. New York: McGrawHill/Irwin, 2009.

Griffin, Jill. Customer Loyalty How to Earn it, How to Keep It.Kentucky: McGraw Hill, 2002. Hye Kyoung Kim, Work-Life Balance and Employees' Performance: The Mediating Role of Affective Commitment, Global Business and Mbhanagement Research: An International Journal Vol. 6, No. 1 (2014).

Koetler, Philip. Marketing Insight from A to Z. New Jersey: John Wiley \& Sons, 2003.

Kreitner, Robert and Angelo Kinicky. Organizational Behavior. New York: McGraw-Hill Irwin, 2010.

Lazar et all, The Role of Work-Life Balance Practices in Order to Improve Organizational Performance, European Research Studies, Volume XIII, Issue (2000).

Locke di dalam Neil Anderson et al, Organizational Psychology (London: Sage Publication, 2001).

Louis P Parker, Peter H. Langford, Work-life balance or work-life alignment? A Test of the importance of work-life balance for employee engagement and intention to stay in organization. Journal of management \& organization, Vol. 14, Issue 3, (2008).

Luthans, Fred. Organizational Behavior. 12 ${ }^{\text {th }}$ edition.New York: McGraw-Hill, 2011.

Jane Sturges, David Guest, Working to Life or living to work, Work life balance early in the career, HRM Journal, Vol.14.

McShane, Steven L, , Mary Ann Von Glinow, Organizational Behavior. New York: McGraw-Hill, 2007.

Malik et. al, Work-Life Balance and Job Satisfaction Among Doctors in Pakistan Malik, Muhammad Imran;Saleem, Farida;Ahmad, Mehboob South Asian Journal of 
Management; Apr-Jun 2010; 17, 2; ABI/INFORM Complete.

Nancy R Lockwood, Work/Life Balance; Challenges and Solution, SHRM Research (2003)

Natalie Skinner dan Janine Chapman, Centre for Work Life (Australia:University of South Australia) 